\title{
Design, optimization and modelling of a chemical recovery system for wet spinning of cellulose in sodium carbonate solutions
}

\author{
Marta Bialik (D) - Anna Jensen • Oula Kotilainen • Ida Kulander • \\ Marta Lopes $(1)$
}

Received: 27 March 2020/ Accepted: 10 August 2020/Published online: 23 August 2020

(C) The Author(s) 2020

\begin{abstract}
The aim of this study is to present the design, optimization and modelling of a chemical recovery system for a novel $\mathrm{CS}_{2}$-free viscose-type process that entails dissolution of pre-treated dissolving pulp in a continuous-flow reactor in cold alkali and wet spinning of cellulose in sodium carbonate solutions. Technologies already known to other industries for the recovery and reuse of chemicals, such as causticizing, recalcination, recarbonization and freeze-separation, were used. Chemical equilibria simulations were performed with OLI Studio 9.5, with the purpose to select experimental conditions which avoid undesired precipitations in each unit operation. Synthetic solutions mimicking the spent coagulation liquor were used in the laboratorial experiments. The proposed chemical recovery system was shown to be technically feasible and reduce chemical make-ups to a minimum of $45 \mathrm{~kg} / \mathrm{ton}$ of $\mathrm{NaOH}$ and $4 \mathrm{~kg} /$ ton of $\mathrm{H}_{2} \mathrm{SO}_{4}$. Small amounts of $\mathrm{Zn}$ are expected to precipitate during recarbonization of the coagulation liquor at $30{ }^{\circ} \mathrm{C}$ and causticizing at $98{ }^{\circ} \mathrm{C}$. Thus, a filter for $\mathrm{ZnO}$ particles should be included in the design of the recarbonization unit and a
\end{abstract}

M. Bialik ( $₫)$ · A. Jensen · I. Kulander · M. Lopes Department Biorefinery and Energy, RISE Research Institutes of Sweden, Drottning Kristinas Väg 61, 11428 Stockholm, Sweden e-mail: marta.bialik@ri.se

O. Kotilainen

Andritz Oy, Tammasaarenkatu 1, 00180 Helsinki, Finland continuous purge of lime mud and input of fresh lime make-up should be needed to keep burnt lime availability at an acceptable level. Overall, the results presented in this study portray a solution to reduce operating costs and the environmental impact of novel viscose-type processes with alkaline spin dopes and wet spinning of cellulose in sodium carbonate solutions.

Keywords Regenerated cellulose - Textile fibre · Chemical recovery $\cdot$ Process modelling · Causticizing · Freeze-crystallization $\cdot$ Recarbonization

\section{Introduction}

The manufacturing of regenerated cellulose fibres involves different chemical and mechanical processes that yield fibres with distinct properties. Viscose, modal, lyocell and cuprammonium rayon are the most common man-made cellulose fibres with application primarily in textile fabrics (Röder et al. 2013). With the growing population and environmental awareness across the world, the demand for sustainable textile fibres is expected to increment at a steady rate. However, the dominant viscose process suffers certain economic and environmental drawbacks, such as the demand for large chemical make-ups $(\mathrm{NaOH}$ and $\mathrm{H}_{2} \mathrm{SO}_{4}$ ) and the use of hazardous carbon disulphide 
$\left(\mathrm{CS}_{2}\right)$ in cellulose xanthation and dissolution. In recent years, a significant amount of research has been done to develop and demonstrate novel $\mathrm{CS}_{2}$-free processes. Among them, the Biocelsol process encompasses a mechano-enzymatic pre-treatment of dissolving pulp for direct dissolution in $\mathrm{NaOH} / \mathrm{ZnO}$ solutions (Vehviläinen et al. 2008, Grönqvist et al. 2015); the CelluNova process entails cellulose dissolution in $\mathrm{NaOH} / \mathrm{urea} /$ thiourea solvent (Kihlman et al. 2010, 2012); the Ioncell-F process uses ionic liquids for cellulose dissolution (Michud et al. 2016); and a more recent process proposes periodate oxidation of pulp followed by crosslinking with chitosan for dissolution of modified cellulose in dilute $\mathrm{NaOH}$ (Alam and Christopher 2017). NeoCel is a novel $\mathrm{CS}_{2^{-}}$ free process that uses dissolution of modified dissolving pulps in a continuous-flow reactor, in cold solutions of sodium zincate in aqueous sodium hydroxide (Grönqvist et al. 2015, Brännvall and Walter 2020) followed by wet spinning of cellulose fibres in either $\mathrm{H}_{2} \mathrm{SO}_{4} / \mathrm{Na}_{2} \mathrm{SO}_{4}$ or $\mathrm{Na}_{2} \mathrm{CO}_{3} / \mathrm{NaOH}$ aqueous solutions. Both NeoCel process variants include a chemical recovery system which is of utmost importance for the reduction of the environmental impact and operating costs associated with make-up chemicals, mainly $\mathrm{NaOH}$ and $\mathrm{H}_{2} \mathrm{SO}_{4}$ (Coutiño and Lopes 2019).

The aim of this study is to present the design, optimization and modelling of the chemical recovery system for the NeoCel process variant with wet spinning of cellulose in sodium carbonate solutions. $\mathrm{Na}_{2} \mathrm{CO}_{3} / \mathrm{NaOH}$ spinning solutions were previously used at semi-pilot scale in the CelluNova research project (Kihlman et al. 2012) and tested again at labscale in the NeoCel research project (2017-2019). This spinning system offers the possibility of using technologies already known to the pulp industry for the recovery and reuse of chemicals, such as causticizing, recalcination and recarbonization. Although the coagulation and stretching conditions of this NeoCel system need further development to yield a fibre with good quality, the theoretical and experimental work presented herein to develop a closedcycle process is unique among the novel $\mathrm{CS}_{2}$-free viscose-type processes. The present study includes: i) design of the chemical recovery system, ii) chemical equilibria simulation of each unit operation, iii) experimental optimization of each unit operation, and iv) modelling and mass balance calculation of the closed-cycle NeoCel process.

\section{Methods}

Samples

Samples of spin dope, spun cellulose fibers and spent coagulation liquor were obtained from a lab-scale wet spinning test in an aqueous solution containing $24 \mathrm{wt} \% \mathrm{Na}_{2} \mathrm{CO}_{3}$ and $2-4 \mathrm{wt} \% \mathrm{NaOH}$ at $30{ }^{\circ} \mathrm{C}$. A sample of industrial burnt lime with 88 wt $\%$ lime availability ( $\mathrm{CaO}$ content) was provided by Andritz Oy (Finland). All these samples were analyzed by ICP-AES to determine their elemental composition. Considering the limited volume of spent coagulation liquor, synthetic solutions mimicking its composition were used in the laboratorial experiments of recarbonization and causticizing. A cellulose hydrolysate was produced in laboratory via alkaline degradation of kraft dissolving pulp, according to the method described by Mozdyniewicz et al. (2013).

Chemical equilibria simulation

Chemical equilibria simulations were performed with OLI Studio 9.5 electrolyte simulator, licensed by OLI Systems Inc., with the purpose to verify the solubility of chemical species at different temperatures and select experimental conditions which maximize the regeneration degree, but at the same time minimize the risk of undesired precipitations in each operation. The simulated chemical systems represented the composition of spent coagulation liquor.

\section{Recarbonization}

Recarbonization experiments were conducted in a 3.8 L Parr reactor equipped with a mechanic stirrer and a sampling line converted into a gas dispenser with a dense sparger. The reaction is very sensitive to the size of the gas bubbles and the mixing speed that were kept as constant as possible. A gas mixture of $\mathrm{CO}_{2}(19.9$ vol $\%), \mathrm{O}_{2}(16.4 \mathrm{vol} \%)$ and $\mathrm{N}_{2}(63.7 \mathrm{vol} \%)$ was used to mimic the composition of industrial flue gases from a lime kiln. The gas mixture was pre-heated to $25-30{ }^{\circ} \mathrm{C}$ and sparged through synthetic solutions containing $24 \mathrm{wt} \% \mathrm{Na}_{2} \mathrm{CO}_{3}, 2 \mathrm{wt} \% \mathrm{NaOH}$ and $0.2 \mathrm{wt} \% \mathrm{ZnO}$ at 
different temperatures. It was not possible to quantify the gas spent in each experiment and estimate the absorption efficiency due to difficulties in measuring weight variations of the gas container.

\section{Causticizing}

Causticizing experiments were conducted in a metal beaker with stirrer placed in a thermostatic water bath to allow temperature control during the experiments. Synthetic solutions with 24 wt $\% \mathrm{Na}_{2} \mathrm{CO}_{3}, 2-4$ wt $\%$ $\mathrm{NaOH}$ and $0.2-0.4 \mathrm{wt} \% \mathrm{ZnO}$ were used in the causticizing trials. Analytical-grade lime was gradually added to the solution up to a molar overcharge of 1.03 in relation to carbonate. The lime availability was 94.2\%, according to SCAN-N 25:81. Each causticizing trial was monitored for $6 \mathrm{~h}$ and three different temperatures were tested: 50,70 and $90{ }^{\circ} \mathrm{C}$. Filtered liquor samples were taken during the course of each causticizing trial and titrated. Some trials were made with industrial lime and synthetic solutions with the above-mentioned composition plus addition of 1.5 wt $\%$ dissolution additive (a modified viscose additive of surfactant type provided by Nouryon) and $0.15 \mathrm{wt} \%$ cellulose hydrolysate.

Freeze-crystallization

Freeze-crystallization experiments were conducted at Andritz Oy (Kotilainen 2017). Synthetic solutions mimicking the composition of causticized coagulation liquor were prepared and loaded into a $1.5 \mathrm{~L}$ jacketed metallic reactor equipped with baffles and a thermal probe. The solution was cooled to $-10^{\circ} \mathrm{C}$ in one step, which took approximately $30 \mathrm{~min}$. Three retention times at $-10{ }^{\circ} \mathrm{C}$ were tested: $10 \mathrm{~min}, 20 \mathrm{~min}$, and 40 min. The $\mathrm{Na}_{2} \mathrm{CO}_{3} \cdot 10 \mathrm{H}_{2} \mathrm{O}$ crystals were separated from the mother liquor by filtration in a $2 \mathrm{~L}$ Büchner flask with WHATMAN GF/A glass fiber filter. Then, crystals were immediately washed with pure ethanol in a $1 \mathrm{~L}$ Büchner flask in order to prevent redissolution. All liquor samples were titrated before and after crystallization and separation to investigate changes in the $\mathrm{Na}_{2} \mathrm{CO}_{3} / \mathrm{NaOH}$ mass ratio.

Process simulation

The full NeoCel mill with spinning in $24 \mathrm{wt} \%$ $\mathrm{Na}_{2} \mathrm{CO}_{3}+2$ wt $\% \mathrm{NaOH}$ solution and chemical recovery was modelled in WinGEMS ${ }^{\circledR} 4.5$, licensed by Valmet. The input parameters where those optimized in the present study for chemical recovery, plus the pre-treatment, dissolution, coagulation and posttreatment operational parameters optimized during the NeoCel project (2017-2019). When operating parameters where unknown, typical industrial parameters from a reference viscose mill were used in the model (Ing. A. Maurer S.A.). Considering the low technological readiness level of this technology, results from modelling have an associated uncertainty.

\section{Results and discussion}

Design of the chemical recovery system

NeoCel comprises dissolution of pre-treated dissolving pulp in a continuous-flow reactor in cold alkali, aided by $\mathrm{Zn}$ and additives, and coagulation of the spin dope optionally in a sodium carbonate solution. The layout of the proposed chemical recovery system for this NeoCel process variant is presented in Fig. 1. During coagulation of the alkaline spin dope in sodium carbonate solution, $\mathrm{NaOH}$ accumulates in the carbonate spin bath. Spinning tests conducted during the NeoCel project have shown that wet spinning of cellulose can effectively run with residual hydroxide concentrations up to $4 \mathrm{wt} \%$. The proposed solution to control the hydroxide level in the spin bath is recarbonization of a circulation stream with $\mathrm{CO}_{2}$-rich flue gases from the lime kiln. Another stream of the coagulation liquor is causticized with lime $(\mathrm{CaO})$ to regenerate $\mathrm{NaOH}$ for cellulose dissolution (Fig. 1). The lime mud $\left(\mathrm{CaCO}_{3}\right)$ formed during causticizing is filtrated, washed and recalcinated in a lime kiln. The causticized solution is further purified by freezecrystallization and separation of $\mathrm{Na}_{2} \mathrm{CO}_{3} \cdot 10 \mathrm{H}_{2} \mathrm{O}$ to meet the quality requirements for cellulose dissolution. All the unit operations mentioned above are known from other industrial applications. However, they need to be optimized or modified for the NeoCel process for best performance and highest product purity.

Recarbonization of the coagulation liquor

Recarbonization, i.e. saturation of the solution with gaseous $\mathrm{CO}_{2}$, was chosen as the optimal method for 


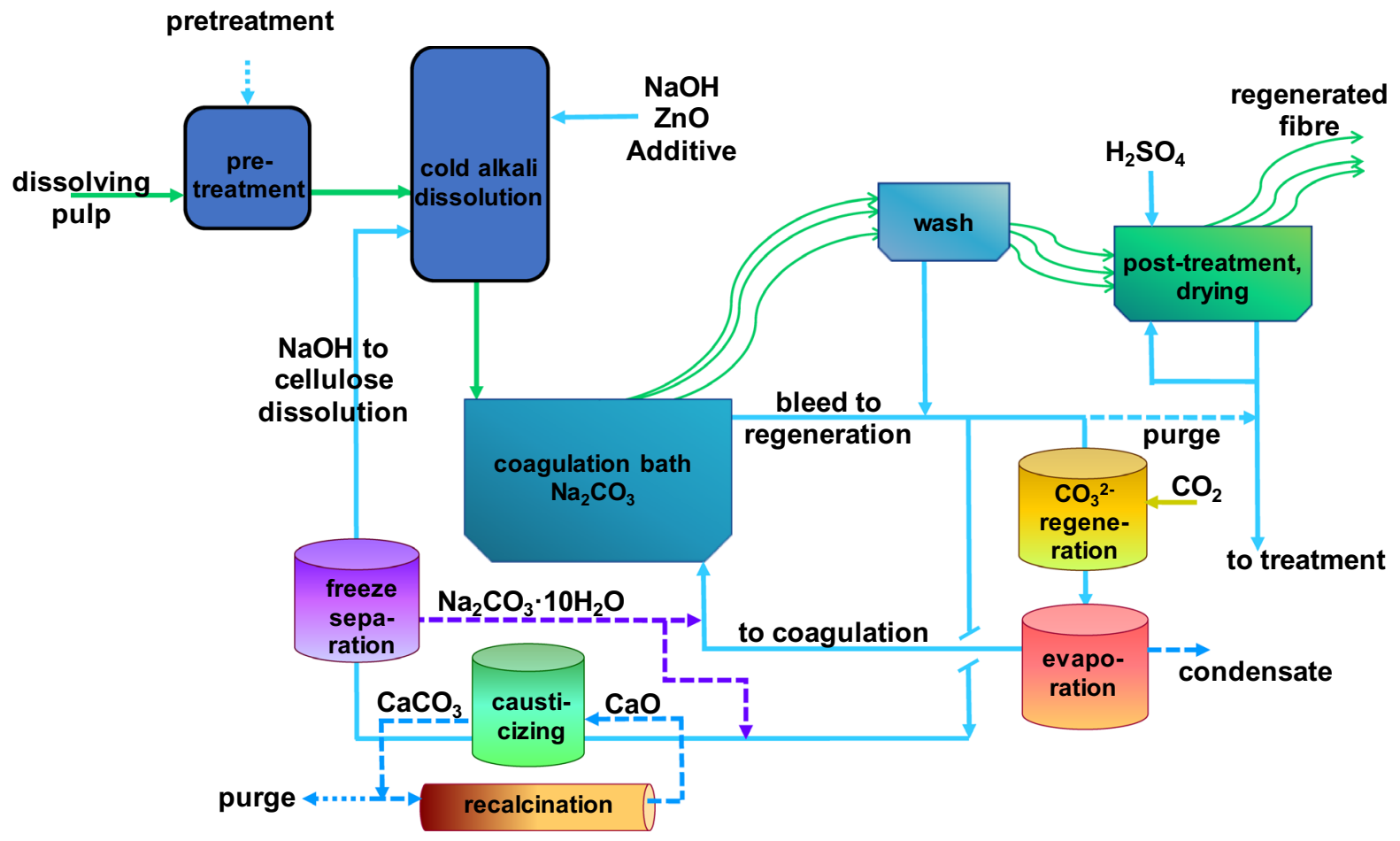

Fig. 1 Process layout of NeoCel with dissolution of cellulose in a continuous-flow reactor in cold alkali, wet spinning in sodium carbonate solution and a chemical recovery system

residual hydroxide control in the coagulation liquor. The reactions proceed as follows:

$\mathrm{CO}_{2}+\mathrm{H}_{2} \mathrm{O} \rightarrow \mathrm{H}_{2} \mathrm{CO}_{3}$

$\mathrm{H}_{2} \mathrm{CO}_{3}+2 \mathrm{OH}^{-} \rightarrow \mathrm{CO}_{3}^{2-}+2 \mathrm{H}_{2} \mathrm{O}$.

This method has been applied in the Lignoboost ${ }^{\circledR}$ process, where $\mathrm{CO}_{2}$ is used to decrease the $\mathrm{pH}$ of black liquor to the point of lignin precipitation (Öhman and Theliander 2007). An additional advantage of this method is the fact that $\mathrm{CO}_{2}$ is easily available in the flue gases of the lime kiln.

A model-solution of the coagulation liquor containing $24 \mathrm{wt} \% \mathrm{Na}_{2} \mathrm{CO}_{3}, 2 \mathrm{wt} \% \mathrm{NaOH}$ and $0.2 \mathrm{wt} \%$ $\mathrm{ZnO}$ was used in the OLI simulation of the recarbonization stage. The recarbonization reaction is exothermic, thus, the temperature and flow of the flue gas must be controlled to avoid overheating of the coagulation liquor. A stepwise addition of $150 \mathrm{~g}$ of $\mathrm{CO}_{2}$ to $1 \mathrm{~kg}$ of solution at different temperatures was simulated in OLI. The evolution of the residual $\mathrm{OH}^{-}$ concentration (Fig. 2), as well as any possible solid formation (Fig. 3), was monitored as the output.
Figure 2 shows that $\mathrm{OH}^{-}$concentration drops almost to zero at a $\mathrm{CO}_{2}$ addition of $12 \mathrm{~g} / \mathrm{kg}$ of solution, within the temperature range of 30 to $50{ }^{\circ} \mathrm{C}$. However, it should be noticed that in a real process there are physical limitations depending on the $\mathrm{CO}_{2}$ absorption rate, diffusion coefficient, size of gas bubbles, etc. Thus, the gas would have to be added in excess, and possibly recirculated.

Figure 3 shows that addition of $\mathrm{CO}_{2}$ above $14 \mathrm{~g} / \mathrm{kg}$ of solution leads to the precipitation of solid phases identified as $\mathrm{NaHCO}_{3} \cdot \mathrm{Na}_{2} \mathrm{CO}_{3} \cdot 2 \mathrm{H}_{2} \mathrm{O}$ and $\mathrm{NaHCO}_{3}$ (the latter at high $\mathrm{CO}_{2}$ additions). This simulation stresses the importance of a proper control of the recarbonization process to avoid precipitation of sodium salts. Another important observation is that $\mathrm{ZnO}$ precipitates as soon as the stabilizing hydroxide ions are removed from solution. This means that the recarbonization step can also be designed to remove the residual $\mathrm{ZnO}$ (s) that might accumulate in the spin bath by adding a particle filter in the recirculating stream.

Experimental recarbonization trials were conducted on a synthetic solution mimicking the spent 


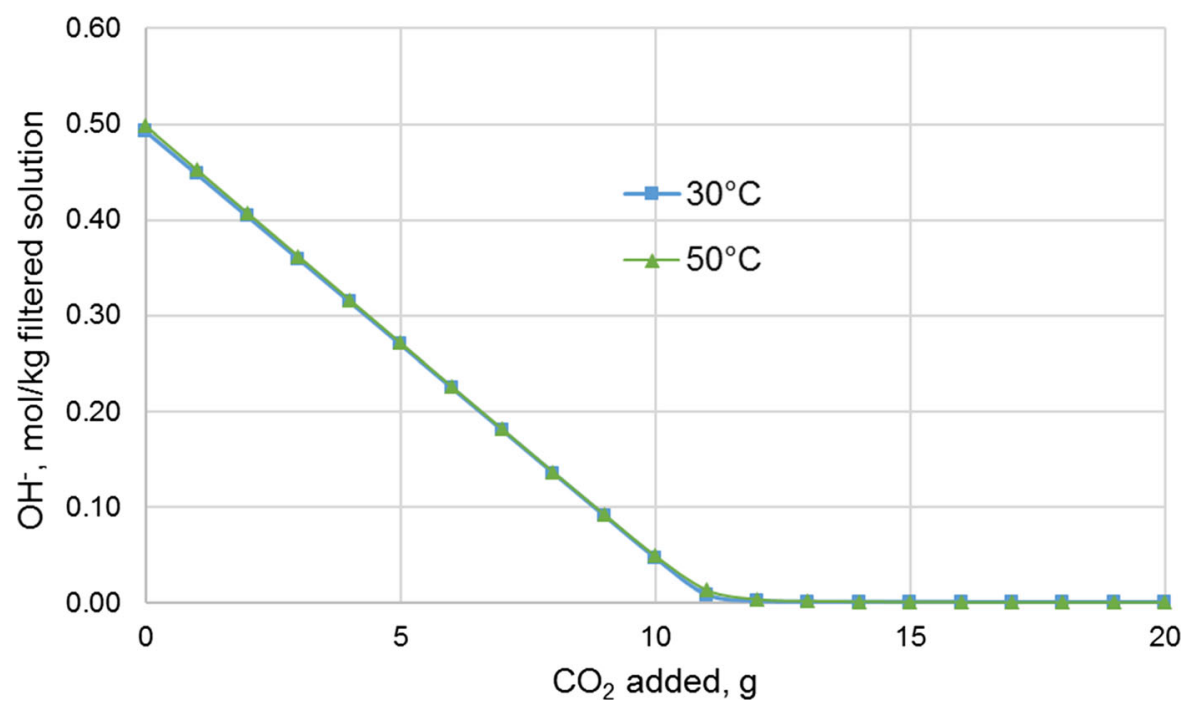

Fig. 2 OLI simulation of the $\mathrm{OH}^{-}$concentration during recarbonization at different temperatures of a model-solution containing 24 $\mathrm{wt} \% \mathrm{Na}_{2} \mathrm{CO}_{3}, 2 \mathrm{wt} \% \mathrm{NaOH}\left(0.5 \mathrm{~mol} \mathrm{OH}^{-} / \mathrm{kg}\right)$ and $0.2 \mathrm{wt} \% \mathrm{ZnO}$

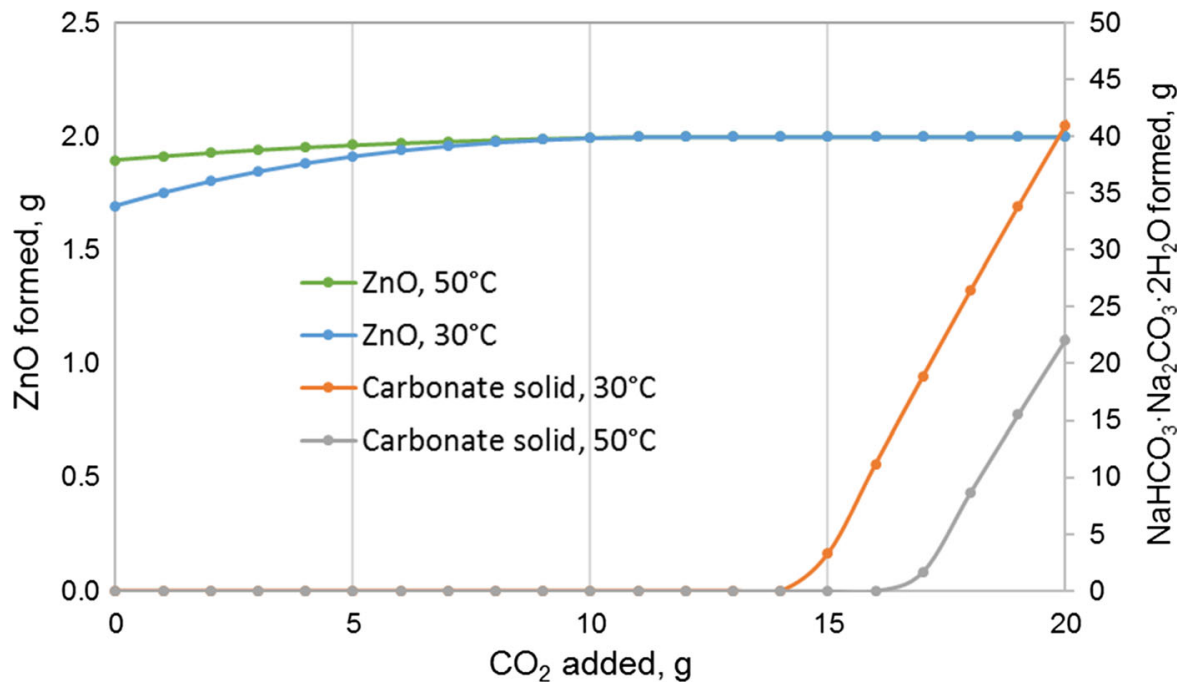

Fig. 3 OLI simulation of the solid phases formed during recarbonization at different temperatures of a model-solution containing 24 $\mathrm{wt} \% \mathrm{Na}_{2} \mathrm{CO}_{3}, 2 \mathrm{wt} \% \mathrm{NaOH}$ and $0.2 \mathrm{wt} \% \mathrm{ZnO}$

coagulation liquor. Figure 4 shows the evolution of the ionic concentrations as a function of the reaction time, at $32{ }^{\circ} \mathrm{C}$ and $60{ }^{\circ} \mathrm{C}$. The laboratorial recarbonization rate at $32{ }^{\circ} \mathrm{C}$ is ca. 1.5 times faster than at $60{ }^{\circ} \mathrm{C}$, with the $\mathrm{OH}^{-}$concentration dropping fivefold in $42 \mathrm{~min}$. The concentration of carbonate ions increased up to $2.53 \mathrm{~mol} / \mathrm{kg}$ (ca. $26 \mathrm{wt} \% \mathrm{Na}_{2} \mathrm{CO}_{3}$ ) upon $50 \mathrm{~min}$ of reaction, and then decreased until the experiment was terminated. This observation is consistent with the formation of sodium bicarbonate precipitates predicted by OLI simulation (Fig. 3). ICPAES analysis of this precipitate also revealed the presence of $\mathrm{Zn}$. These results confirm the need to include a particle filter in the recirculation stream of an industrial recarbonization process. As long as the recarbonization is controlled so that the overcharge of $\mathrm{CO}_{2}$, and the resulting precipitation of carbonate salts, are avoided, the only solid formed in this stage will be $\mathrm{ZnO}$. After a displacement washing to remove the 


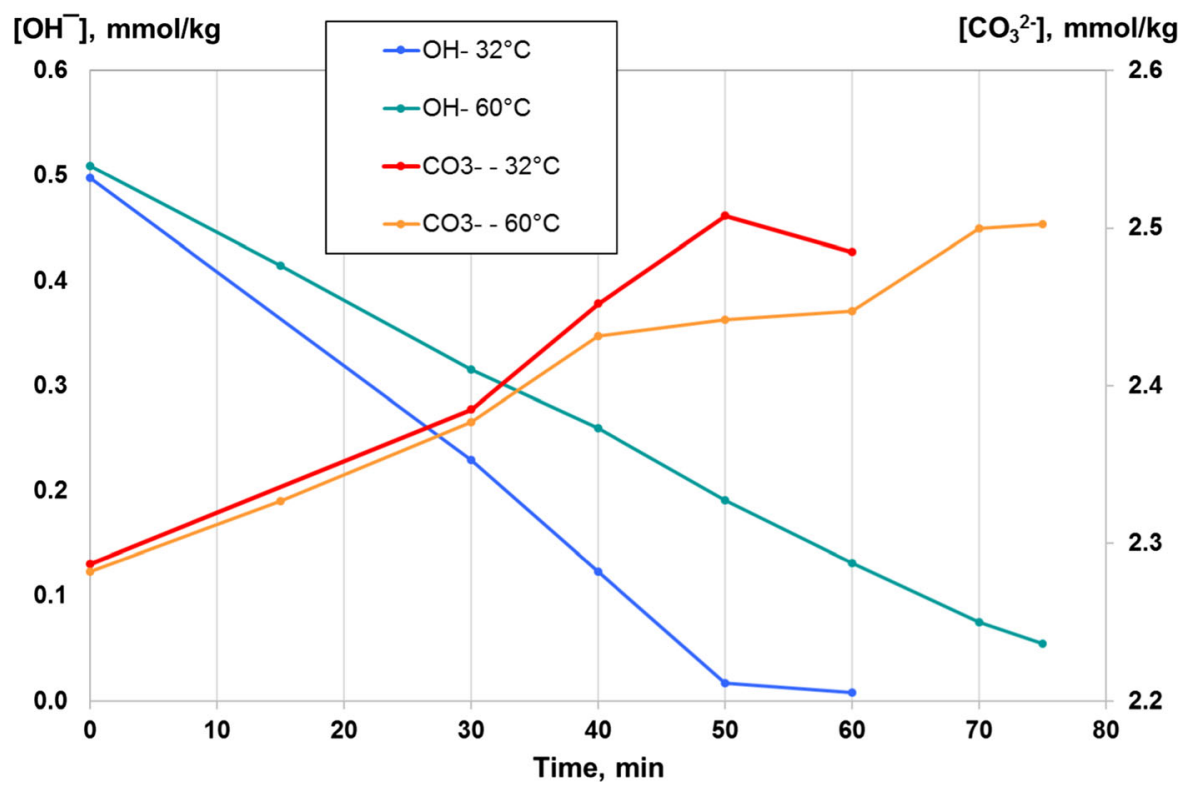

Fig. 4 Experimental ion concentrations upon recarbonization of a synthetic solution containing 24 wt $\% \mathrm{Na}_{2} \mathrm{CO}_{3}, 2 \mathrm{wt} \% \mathrm{NaOH}$ and $0.2 \mathrm{wt} \% \mathrm{ZnO}$ as a function of time and temperature

carryover of the recarbonised solution, $\mathrm{ZnO}$ can be returned directly to the alkali preparation stage.

The industrial recarbonization process would require an accurate system of process control to keep the $\mathrm{CO}_{2}$ absorption at an appropriate level. Increasing the reaction temperature could be one of the practical solutions-the recarbonization rate would decrease and salt solubilities would increase. Moreover, as the spin dope is injected into the coagulation liquor at low temperature $\left(0-15{ }^{\circ} \mathrm{C}\right)$, the recirculation stream that is recarbonized can be heated to temperatures above $30{ }^{\circ} \mathrm{C}$ to keep the coagulation bath controlled at $30{ }^{\circ} \mathrm{C}$.

Causticizing of the coagulation liquor

In the causticizing stage, the coagulation liquor reacts with lime in order to regenerate $\mathrm{NaOH}$ in two steps:

$$
\begin{aligned}
& \mathrm{CaO}(\mathrm{s})+\mathrm{H}_{2} \mathrm{O} \rightarrow \mathrm{Ca}(\mathrm{OH})_{2}(\mathrm{~s}) \\
& \mathrm{Ca}(\mathrm{OH})_{2}(\mathrm{~s})+2 \mathrm{Na}^{+}+\mathrm{CO}_{3}^{2-} \\
& \leftrightarrow \mathrm{CaCO}_{3}(\mathrm{~s})+2 \mathrm{Na}^{+}+2 \mathrm{OH}^{-} .
\end{aligned}
$$

In the first step, called slaking reaction, solid $\mathrm{CaO}$ reacts with water to form solid $\mathrm{Ca}(\mathrm{OH})_{2}$, which then reacts with dissolved carbonate in the so called causticizing reaction to form solid $\mathrm{CaCO}_{3}$ (lime mud) and caustic soda. The first reaction is strongly exothermic and instantaneous, $-67 \mathrm{~kJ} / \mathrm{mol}$ at $100{ }^{\circ} \mathrm{C}$ (Ulmgren et al. 1999), limited only by the mass transfer from the solid $\mathrm{CaO}$ particles. The second reaction is weakly exothermic, $-7.6 \mathrm{~kJ} / \mathrm{mol}$ at infinite dilution (Theliander 1992), and its extent is strongly dependent on temperature. The reaction is fully reversible in practical industrial conditions, meaning that the maximum conversion degree of carbonate into $\mathrm{OH}^{-}$is thermodynamically limited. In practice, a noticeable amount of residual carbonate will always be present in the causticized solution. The final causticizing efficiency (CE), calculated as follows, will be higher at lower reaction temperatures.

Causticizing efficiency $(\mathrm{CE})=\frac{\left[\mathrm{OH}^{-}\right]}{\left[\mathrm{OH}^{-}\right]+2\left[\mathrm{CO}_{3}^{2-}\right]}$

OLI simulations were used in a series of exercises aiming at investigating the theoretical limits of the causticizing stage for the NeoCel process. In most simulations, $800 \mathrm{~g}$ of two model-solutions containing 24 wt $\% \mathrm{Na}_{2} \mathrm{CO}_{3}, 2-4$ wt $\% \mathrm{NaOH}$ and $0.2-0.4$ wt $\%$ $\mathrm{ZnO}$ were causticized with $110 \mathrm{~g}$ of pure $\mathrm{CaO}$, which corresponds to a lime molar ratio of 1.03. Figure 5 shows the predicted final concentration of soluble species at different causticizing temperatures and Fig. 6 shows the predicted precipitates formed at 


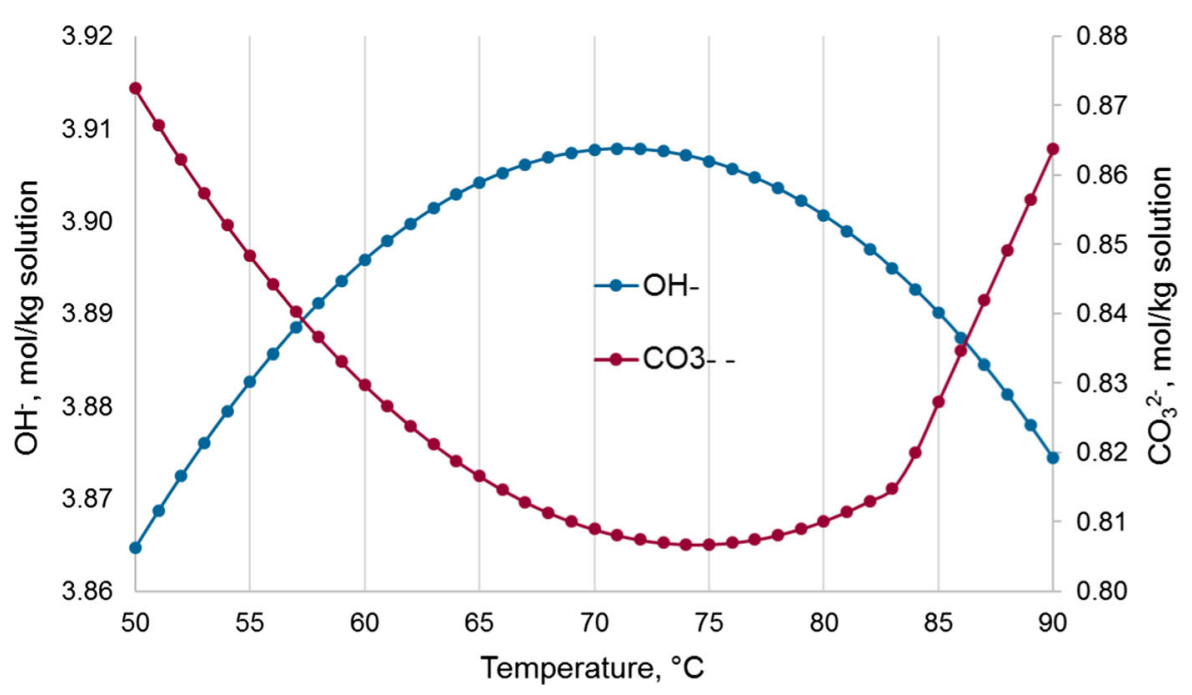

Fig. 5 OLI concentrations of $\mathrm{OH}^{-}$and $\mathrm{CO}_{3}{ }^{2-}$ as total ions, including $\mathrm{Na}(\mathrm{OH})\left(\mathrm{CO}_{3}\right)^{2-}$, in the causticized model-solution at different temperatures

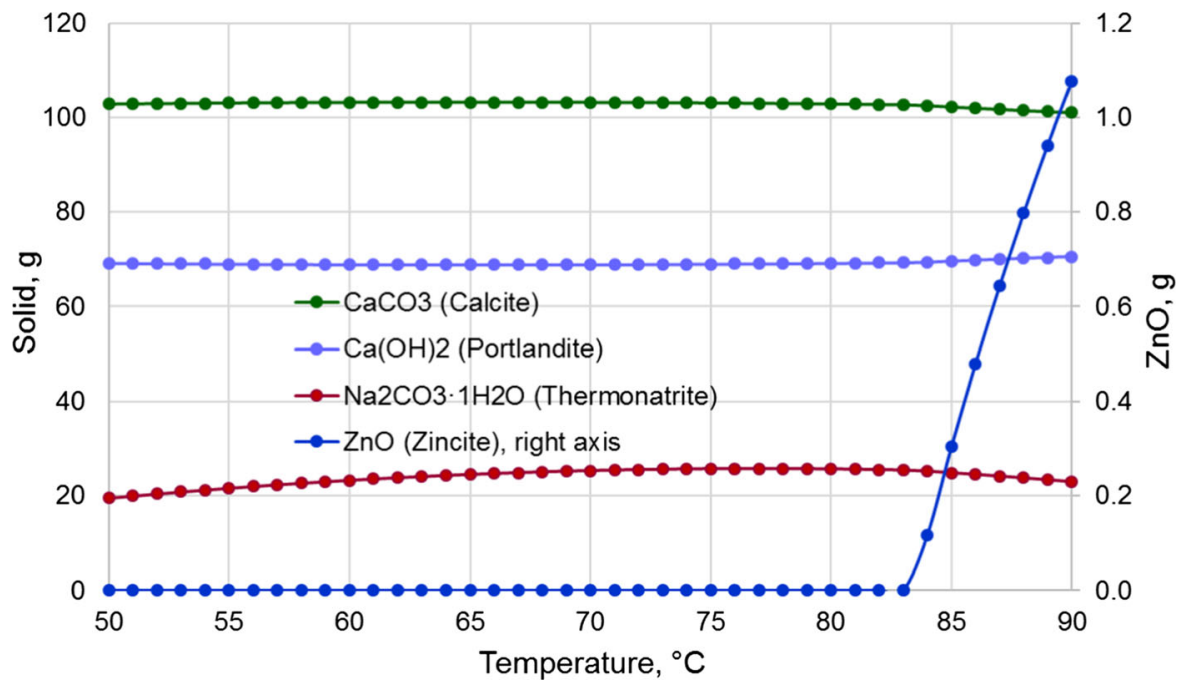

Fig. 6 Mass of solids predicted by OLI to be formed in the causticized model-solution at different temperatures

different causticizing temperatures for an initial $\mathrm{NaOH}$ concentration of $4 \mathrm{wt} \%$. OLI simulations showed that the initial concentration of $\mathrm{NaOH}, 2$ wt $\%$ or $4 \mathrm{wt} \%$, did not have a significant influence on the causticizing efficiency, which reaches a maximum value at $70-75{ }^{\circ} \mathrm{C}$ (Fig. 5). It also predicted the precipitation of $\mathrm{ZnO}$ (s) at causticizing temperatures above $84{ }^{\circ} \mathrm{C}$ and precipitation of thermonatrite $\left(\mathrm{Na}_{2}\right.$ $\mathrm{CO}_{3} \cdot \mathrm{H}_{2} \mathrm{O}$ ) over the whole studied temperature range (Fig. 6). Since industrial experience has shown that pirssonite $\left(\mathrm{Na}_{2} \mathrm{Ca}\left(\mathrm{CO}_{3}\right)_{2} \cdot 2 \mathrm{H}_{2} \mathrm{O}\right)$ precipitates in causticizing systems and not thermonatrite (Frederick et al. 1990), chemical analysis was later conducted on the precipitate formed during experimental causticizing trials to confirm its composition. The reason for this possible misidentification was that pirssonite was missing in the OLI Studio 9.5 database.

Precipitation of pirssonite is undesired because it leads to an effective loss of alkali in the causticized solution and high sodium content in the lime mud that affects recalcination efficiency (Frederick et al. 1990). Solubility data published by Frederick et al. (1990), 
Ulmgren et al. (1999) and Zakir et al. (2013) were used to estimate the safe ion concentration in the causticizing stage (Fig. 7). The solubility in the system relevant for this work, i.e. solutions containing $\mathrm{Na}_{2} \mathrm{CO}_{3}-\mathrm{NaOH}-\mathrm{CaCO}_{3}-\mathrm{H}_{2} \mathrm{O}$, was evaluated only at $95{ }^{\circ} \mathrm{C}$ and no extrapolation to other temperatures can safely be made.

Pirssonite solubility data was applied on the OLI simulation of the model-solution with $24 \mathrm{wt} \% \mathrm{Na}_{2}$ $\mathrm{CO}_{3}, 4 \mathrm{wt} \% \mathrm{NaOH}$ and $0.4 \mathrm{wt} \% \mathrm{ZnO}$ and it was observed that upon causticizing $\mathrm{CO}_{3}{ }^{2-}$ concentrations were always above the pirssonite solubility limit (not shown). A pre-dilution of the model-solution to $63 \%$ of its original concentration was needed to keep $\mathrm{CO}_{3}{ }^{2-}$ concentration always below the pirssonite solubility limit during causticizing at $95{ }^{\circ} \mathrm{C}$. As a safety margin, a dilution to $60 \%$ of its original concentration should be employed (Fig. 8). Summing up, the optimal temperature for causticizing the spent coagulation liquor would be $70-75^{\circ} \mathrm{C}$. However, to avoid pirssonite precipitation the causticizing stage would have to be operated at maximum temperature possible $\left(95-98{ }^{\circ} \mathrm{C}\right)$ to increase salt solubilities and be preceded by dilution of the liquor to $60 \%$ of the initial carbonate concentration. Nevertheless, co-precipitation of the residual $\mathrm{ZnO}$ with lime mud would be unavoidable at $95-98{ }^{\circ} \mathrm{C}$, as shown in Fig. 6.
Experimental causticizing trials at $70{ }^{\circ} \mathrm{C}$ were conducted on synthetic solutions mimicking the spent coagulation liquor. A sample of the precipitate formed was separated and analysed by X-ray diffraction. The diffractogram confirmed the presence of $\mathrm{CaCO}_{3}$ formed during causticizing, unreacted $\mathrm{Ca}(\mathrm{OH})_{2}$ and pirssonite $\mathrm{CaCO}_{3} \cdot \mathrm{Na}_{2} \mathrm{CO}_{3} \cdot 2 \mathrm{H}_{2} \mathrm{O}$.

Additional laboratorial causticizing trials were conducted at $98{ }^{\circ} \mathrm{C}$ with industrial lime on synthetic solutions with 24 wt $\% \mathrm{Na}_{2} \mathrm{CO}_{3}, 4$ wt $\% \mathrm{NaOH}$ and $0.4 \mathrm{wt} \% \mathrm{ZnO}$, with and without pre-dilution to $60 \%$ of the original carbonate concentration (Fig. 9). Moreover, $1.5 \mathrm{wt} \%$ dissolution-aid additive (a modified viscose additive of surfactant type provided by Nouryon) and $1.5 \mathrm{wt} \%$ cellulose hydrolysate was added to the synthetic solution to evaluate the impact of accumulated impurities on the causticizing efficiency of the spent coagulation liquor. It should be mentioned that these concentrations of additive and carbohydrates are quite above the expected steady-state values in a NeoCel process. Figure 9 shows that the maximum causticizing efficiency was reached after 3-4 h of reaction for all cases, which is comparable to causticizing reaction times of green liquor in pulp mills. The pre-dilution of the synthetic coagulation solution lead, as expected, to an increase of the causticizing efficiency from 78 to $89 \%$, which is

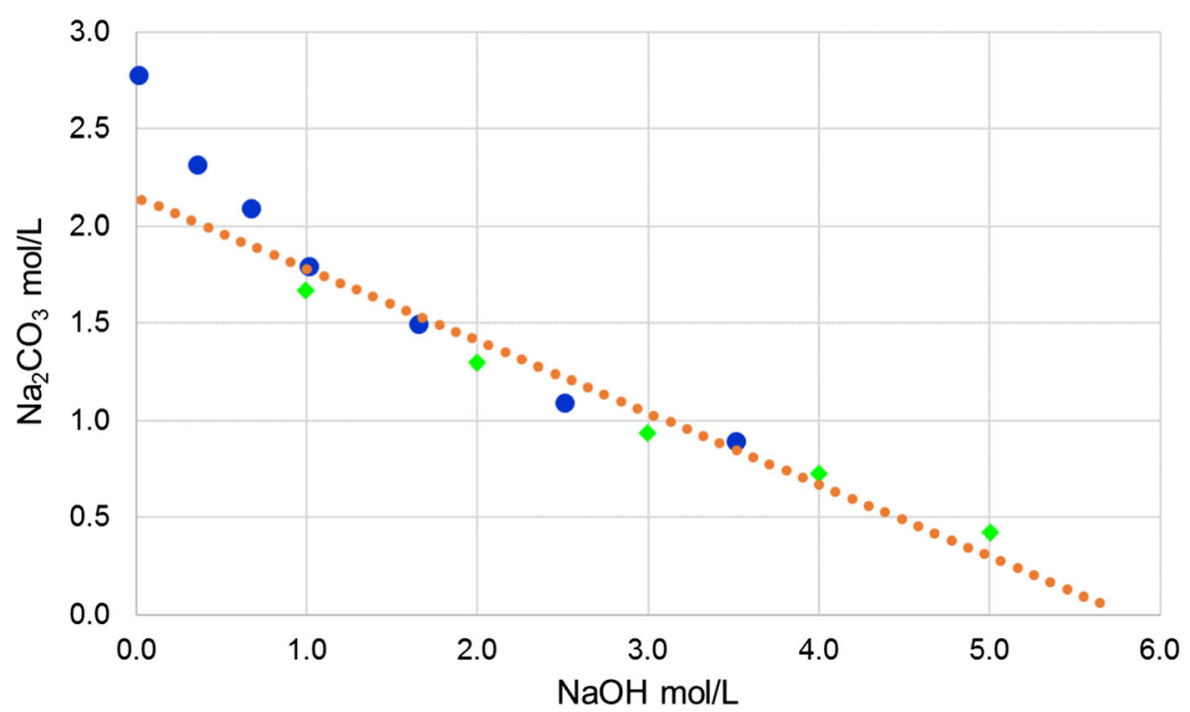

Fig. 7 Solubility of pirssonite at $95{ }^{\circ} \mathrm{C}$ in solutions containing $\mathrm{Na}_{2} \mathrm{CO}_{3}-\mathrm{NaOH}-\mathrm{CaCO}_{3}-\mathrm{H}_{2} \mathrm{O}$. Experimental data of: $\diamond$ Frederick et al. (1990), • Zakir et al. (2013), and $\cdots$ model of Ulmgren et al. (1999) 


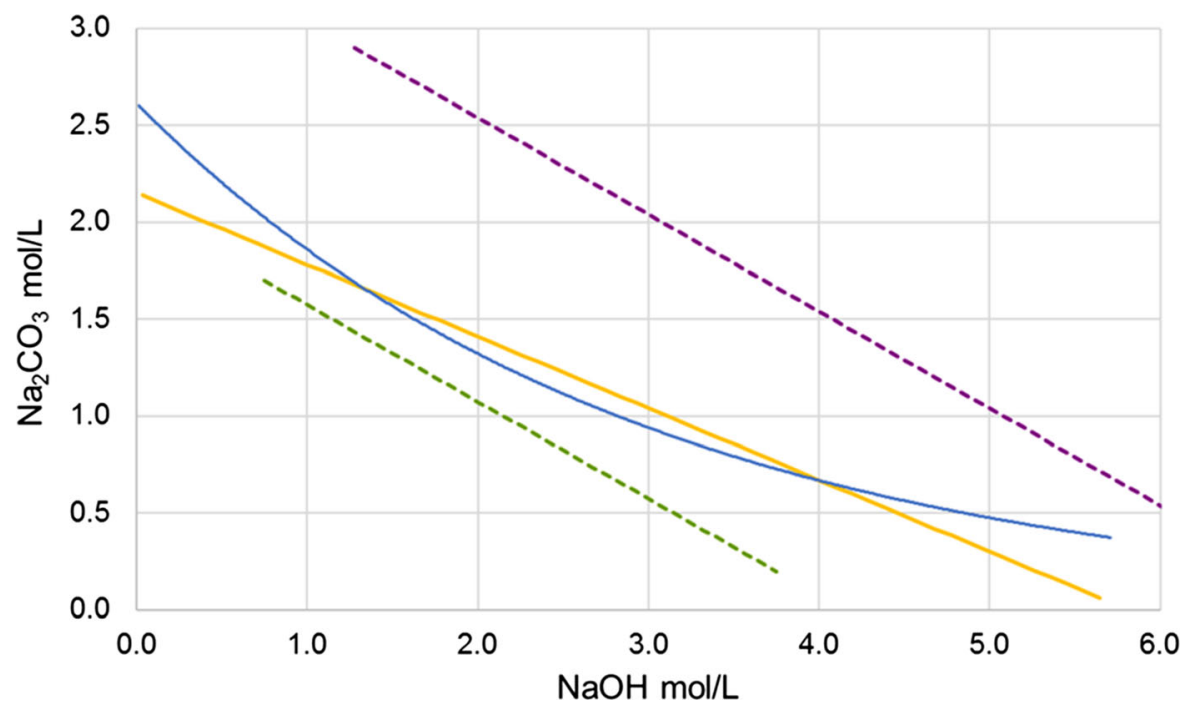

Fig. 8 Theoretical concentrations of $\mathrm{CO}_{3}{ }^{2-}$ and $\mathrm{OH}^{-}$during causticizing at $95{ }^{\circ} \mathrm{C}$ for the original solution (---), and the solution diluted to $60 \%$ of its original concentration (---), compared to the approximate solubility limit for pirssonite published by Zakir et al. 2013 (-) and Ulmgren et al. 1999 (-)

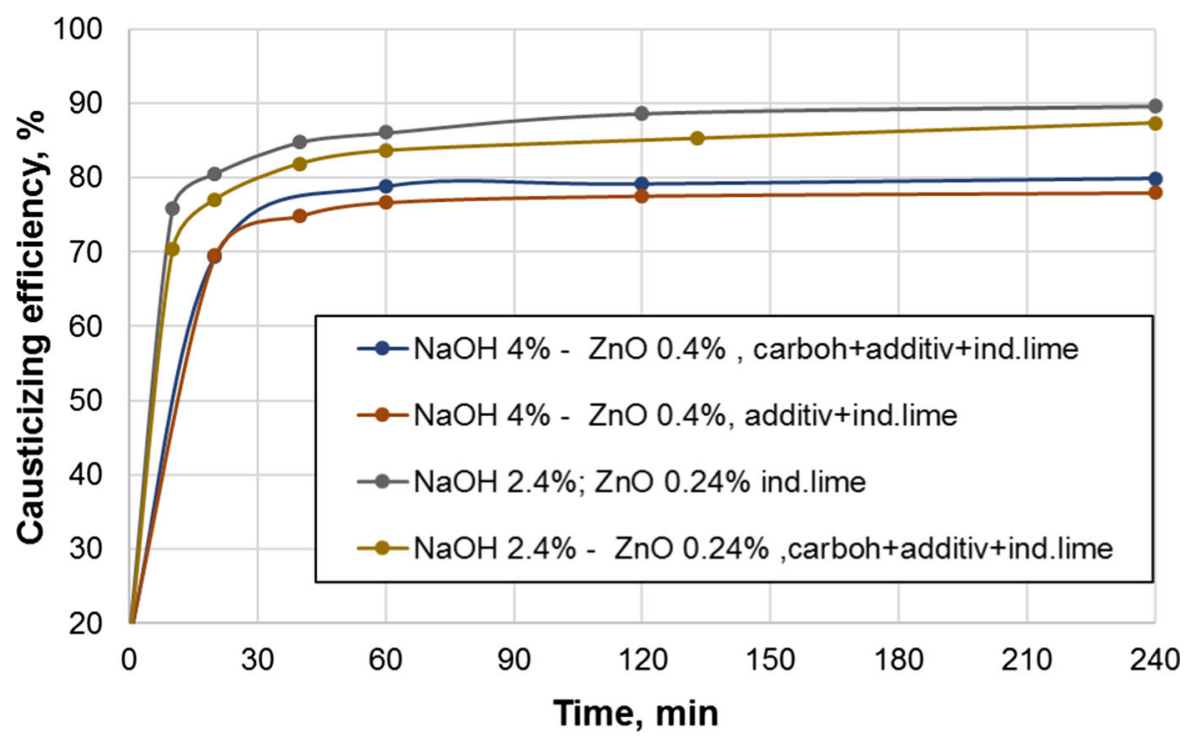

Fig. 9 Experimental $\mathrm{CE}$ of synthetic solutions containing $24 \mathrm{wt} \% \mathrm{Na}_{2} \mathrm{CO}_{3}, 4 \mathrm{wt} \% \mathrm{NaOH}, 0.4 \mathrm{wt} \% \mathrm{ZnO}$, causticized with industrial lime at $98{ }^{\circ} \mathrm{C}$, with and without pre-dilution and addition of $1.5 \mathrm{wt} \%$ additive and $1.5 \mathrm{wt} \%$ carbohydrates

higher than typical efficiencies (80-83\%) obtained at green liquor causticizing plants in pulp mills (Frederick et al. 1990). As the cellulose dissolution stage requires low content of residual $\mathrm{CO}_{3}{ }^{2-}$, the high causticizing efficiency is beneficial to the process since it reduces the need for further carbonate removal. Hence, the only limiting factor is the risk for pirssonite precipitation, discussed above. The addition of carbohydrates and additive to the synthetic coagulation solutions reduced slightly the CE in $3 \%$ points (Fig. 9).

Analysis of non-process elements (NPEs) were conducted on the industrial lime and corresponding lime muds produced during the causticizing experiments at $98{ }^{\circ} \mathrm{C}$ and reported in Fig. 10 based on the mass of $\mathrm{Ca}$. Assuming that $\mathrm{Ca}$ is not dissolved or 


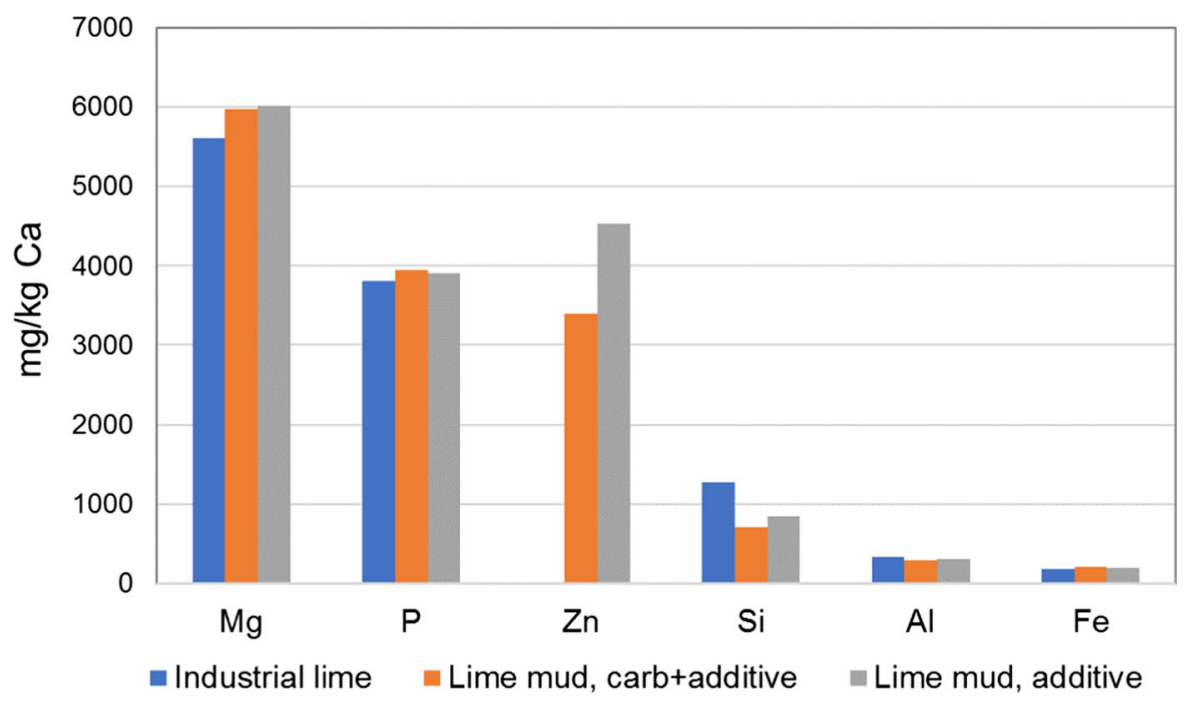

Fig. 10 Elemental composition normalized to the mass of $\mathrm{Ca}$ of the industrial lime and lime muds obtained by causticizing at $98{ }^{\circ} \mathrm{C}$ the synthetic liquor with additive and additive plus carbohydrates

added by any other way during causticizing, this way of presenting the elemental composition of lime and lime muds allows a straightforward comparison of the changes in NPE content. Apart from $\mathrm{Ca}$, the main NPEs in the industrial lime are $\mathrm{Mg}, \mathrm{P}$ and $\mathrm{Si}$ (Fig. 10). No risk for $\mathrm{Mg}, \mathrm{P}, \mathrm{Al}$ and $\mathrm{Fe}$ accumulation in the causticized liquors was detected, as the relative content of these NPEs didn't vary significantly between lime and corresponding lime muds. On the other hand, $\mathrm{Zn}$ accumulation was observed in the lime mud (Fig. 10) as predicted by OLI simulations for causticizing temperatures above $84{ }^{\circ} \mathrm{C}$ (Fig. 6). This means that a continuous purge of lime mud before the lime kiln and a fresh lime make-up in the causticizing stage would be required to keep lime availability at an acceptable level.

The high content of $\mathrm{Zn}$ in the used lime mud arises some concerns, e.g. costs of $\mathrm{ZnO}$ makeup as well as the economic and environmental effects associated with the purged lime mud stream. In this work, we have chosen to keep the lime availability constant and to avoid the $\mathrm{Zn}$ build-up by extensive lime purge. However, another possible solution would include allowing the lime availability to drop from $80 \%$ assumed in the simulation to $\sim 70-75 \%$ (realistic lowest range for an industrial lime) at the expense of the higher deadload and higher fuel consumption in the lime kiln. As the maximum $\mathrm{Zn}$ accumulation in the lime mud has not been investigated in this work, it is possible that, at some level, a steady-state would be reached between the $\mathrm{Zn}$ precipitation into the lime mud and the dissolution into the newly causticized solution. In any case, either a means for the safe disposal of the purged lime mud or a method of recovering $\mathrm{Zn}$ from it should be investigated in the future. So far, no technical solution for the recovery of $\mathrm{ZnO}$ from the lime mud has been developed; an investigation of possible methods is proceeding.

Freeze-crystallization and separation of $\mathrm{Na}_{2} \mathrm{CO}_{3} \cdot 10 \mathrm{H}_{2} \mathrm{O}$

An additional stage is needed in NeoCel to increase the purity of the causticized liquor to be reused in the process as $\mathrm{NaOH}$ source. In the proposed freezecrystallization stage, the causticized liquor is cooled to $-10{ }^{\circ} \mathrm{C}$ for a certain time to crystallize the residual sodium carbonate as $\mathrm{Na}_{2} \mathrm{CO}_{3} \cdot 10 \mathrm{H}_{2} \mathrm{O}(\mathrm{s})$, which is later separated from the $\mathrm{NaOH}$-enriched liquor by filtration or centrifugation (Fig. 1). Optimization of the freezecrystallization stage for the NeoCel process was conducted at Andritz Oy (Finland) with synthetic solutions. Results of the laboratorial tests are shown in Table 1. At the time these experiments were done, the optimization of the causticizing stage had not yet been completed. Thus, the synthetic solution that should mimic the causticized liquor had a lower CE (76\%) than the values found after causticizing the pre-diluted 
Table 1 Composition of synthetic solutions before and after freeze-

crystallization at $-10^{\circ} \mathrm{C}$

\begin{tabular}{lllll}
\hline & Before & After 10 min & After 20 min & After 40 min \\
\hline $\mathrm{NaOH}(\mathrm{g} / \mathrm{l})$ & 184 & 208 & 209 & 206 \\
$\mathrm{Na}_{2} \mathrm{CO}_{3}(\mathrm{~g} / \mathrm{l})$ & 78 & 16 & 15 & 17 \\
$\mathrm{CE}(\%)$ & 76 & 94 & 95 & 94 \\
$\mathrm{Na}_{2} \mathrm{CO}_{3} / \mathrm{NaOH}(\mathrm{m} / \mathrm{m})$ & 0.43 & 0.076 & 0.074 & 0.084 \\
\hline
\end{tabular}

liquors at $98{ }^{\circ} \mathrm{C}(85-89 \%)$. In other words, the relative amount of $\mathrm{Na}_{2} \mathrm{CO}_{3} \cdot 10 \mathrm{H}_{2} \mathrm{O}$ (s) to be separated would be smaller than initially estimated. Results in Table 1 show that the $\mathrm{NaOH}$-enriched liquor with highest purity was obtained with $20 \mathrm{~min}$ of retention time at $-10{ }^{\circ} \mathrm{C}$. The laboratorial filtration of the frozen crystals was a bit challenging as they start to redissolve at room temperature. Nevertheless, a $\mathrm{Na}_{2} \mathrm{CO}_{3} / \mathrm{NaOH}$ mass ratio of 0.074 was achieved in this experiment, which complies with the purity requirements determined by the mass balance of the NeoCel process simulated in WinGEMS ${ }^{\circledR}$.

At a first glance, the freeze-crystallization stage for the large flow of the circulating liquor would require considerable amounts of extra energy. It should, however, be noticed that extensive cooling is anyway needed for the process as the cellulose dissolution is conducted at low temperature, $-3{ }^{\circ} \mathrm{C}$. A part of the cooling demand for the dissolution stage can therefore advantageously be satisfied by mixing the cellulose stream with low-temperature alkali coming from the freeze-crystallization stage, thus reducing the costs.

\section{Process modelling}

The full NeoCel mill was modelled in WinGEMS ${ }^{\circledR}$ with the purpose to simulate a steady-state operation and detect possible limitations, interactions and synergies in an early design phase. Table 2 presents the chemical consumptions of the modelled NeoCel process compared to a reference viscose process. The savings in $\mathrm{NaOH}$ make-up enabled by the chemical recovery system are quite significant. The savings in the cost for $\mathrm{H}_{2} \mathrm{SO}_{4}$ consumption are related to the fact that this NeoCel process variant doesn't use an acidic bath for wet spinning of cellulose, as the viscose process does. A small amount of $\mathrm{H}_{2} \mathrm{SO}_{4}$ is only used in post-treatment fibre washing whose effluents are discarded to treatment.

The dilution of the spent coagulation liquor going to the causticizing plant was achieved using washing
Table 2 Chemical consumptions obtained by WinGEMS ${ }^{\circledR}$ modelling of $\mathrm{NeoCel}$ and a reference viscose process using sulphite dissolving pulp

\begin{tabular}{llll}
\hline & Units & NeoCel & Viscose \\
\hline Sulfite dissolving pulp & $\mathrm{t} / \mathrm{t}$ fibre & 1.01 & 1.01 \\
Enzyme & $\mathrm{kg} / \mathrm{t}$ fibre & 5 & 0 \\
$\mathrm{CS}_{2}$ & $\mathrm{~kg} / \mathrm{t}$ fibre & 0 & 75 \\
$\mathrm{NaOH}$ & $\mathrm{kg} / \mathrm{t}$ fibre & 45 & 606 \\
$\mathrm{H}_{2} \mathrm{SO}_{4}$ & $\mathrm{~kg} / \mathrm{t}$ fibre & 4 & 840 \\
$\mathrm{ZnO}_{\mathrm{ZnSO}}$ & $\mathrm{kg} / \mathrm{t}$ fibre & 60 & 0 \\
$\mathrm{Additives}$ & $\mathrm{kg} / \mathrm{t}$ fibre & 0 & 35 \\
$\mathrm{Acetic}$ acid & $\mathrm{kg} / \mathrm{t}$ fibre & 4 & 9.5 \\
$\mathrm{CaO}$ & $\mathrm{kg} / \mathrm{t}$ fibre & 15 & 15 \\
Natural gas & $\mathrm{kg} / \mathrm{t}$ fibre & 410 & 0 \\
\hline & $\mathrm{MWh} / \mathrm{t}$ fibre & 0.59 & 0 \\
\hline
\end{tabular}

filtrate from the fibre post-treatment plant. This results in freshwater savings and recovers some sodium into the process, that otherwise would be lost to the wastewater plant. The mass balance obtained in WinGEMS $^{\circledR}$ indicates that the diluted coagulation liquor would have the following composition: $16 \mathrm{wt} \%$ $\mathrm{Na}_{2} \mathrm{CO}_{3}, 1.3$ wt $\% \mathrm{NaOH}, 0.12 \mathrm{wt} \% \mathrm{ZnO}, 0.05$ wt $\%$ additive, and $0.008 \mathrm{wt} \%$ cellulose hydrolysate. These are much lower concentrations of additive and carbohydrates than those in the synthetic liquors used in laboratory for optimisation of the causticizing stage. Only a long spinning trial could provide representative samples of the spent coagulation liquor to validate the concentration of accumulated impurities. After the causticizing stage, $29 \%$ of the water in the causticized liquor needs to be removed by evaporation and/or freeze-crystallization. According to the mass balances obtained in WinGEMS ${ }^{\circledR}$, when the $\mathrm{NaOH}$-enriched liquor from freeze-crystallization reaches a maximum $\mathrm{Na}_{2} \mathrm{CO}_{3} / \mathrm{NaOH}$ mass ratio of 0.14 , the concentration of $\mathrm{Na}_{2} \mathrm{CO}_{3}$ in the spin dope reaches $1 \mathrm{wt} \%$, which is the limit concentration of $\mathrm{Na}_{2} \mathrm{CO}_{3}$ in industrial grade 
caustic soda. Experimental results presented in Table 1 demonstrate that a $\mathrm{Na}_{2} \mathrm{CO}_{3} / \mathrm{NaOH}$ mass ratio of 0.08 is easily achieved at $-10{ }^{\circ} \mathrm{C}$, which yields rather low concentration of $\mathrm{Na}_{2} \mathrm{CO}_{3}$ in the spin dope $(<0.6 \mathrm{wt} \%)$.

\section{Conclusions}

Based on the simulations and laboratorial experiments presented in this study, the proposed chemical recovery system for the NeoCel process with wet spinning of cellulose in sodium carbonate solutions is technically feasible and reduces chemical make-ups to a minimum of $45 \mathrm{~kg} / \mathrm{ton}$ of $\mathrm{NaOH}$ and $4 \mathrm{~kg} / \mathrm{ton}$ of $\mathrm{H}_{2} \mathrm{SO}_{4}$. Small amounts of $\mathrm{Zn}$ are expected to precipitate during recarbonization at $30{ }^{\circ} \mathrm{C}$ and causticizing at $98{ }^{\circ} \mathrm{C}$ of the coagulation liquor. Thus, a filter for $\mathrm{ZnO}$ particles should be included in the design of the recarbonization unit and a continuous purge of lime mud and input of fresh lime make-up should be needed to keep burnt lime availability at an acceptable level. $\mathrm{ZnO}$ precipitated during the recarbonization stage can be returned to the process; in the future, means for $\mathrm{Zn}$ recovery from lime mud might also be developed. Overall, the results presented in this study portray a solution to reduce operating costs and the environmental impact of novel viscose-type processes with alkaline spin dopes and wet spinning of cellulose in sodium carbonate solutions.

Acknowledgments All the partners in NeoCel Project are gratefully acknowledged for the support and valuable feedback on this manuscript.

Funding Open access funding provided by RISE Research Institutes of Sweden. This research was conducted within the Project "NeoCel" that received funding from the Bio Based Industries Joint Undertaking within the European Union's Horizon 2020 research and innovation program, under Grant Agreement No. 720729.

Availability of data and material All numerical data except for those related to freeze-crystallization experiments are available upon request at RISE Research Institutes of Sweden. Data pertaining to freeze-crystallization experiments can be obtained from Kotilainen (2017). Materials used in the experiments are the property of the NeoCel project and might be viewed upon permission from the project consortium.

Code availability Commercial licenses for Microsoft Office and for OLI Analyser software, purchased by RISE Research Institutes of Sweden, were used in this Project.

\section{Compliance with ethical standards}

Conflict of interest The authors declare that they have no conflict of interest.

Open Access This article is licensed under a Creative Commons Attribution 4.0 International License, which permits use, sharing, adaptation, distribution and reproduction in any medium or format, as long as you give appropriate credit to the original author(s) and the source, provide a link to the Creative Commons licence, and indicate if changes were made. The images or other third party material in this article are included in the article's Creative Commons licence, unless indicated otherwise in a credit line to the material. If material is not included in the article's Creative Commons licence and your intended use is not permitted by statutory regulation or exceeds the permitted use, you will need to obtain permission directly from the copyright holder. To view a copy of this licence, visit http://creativecommons.org/licenses/by/4.0/.

\section{References}

Alam MN, Christopher LP (2017) A novel, cost-effective and eco-friendly method for preparation of textile fibres from cellulosic pulps. Carbohydr Polym 173:253-258. https:// doi.org/10.1016/j.carbpol.2017.06.005

Brännvall E, Walter K (2020) Kraft process modifications to obtain dissolving pulp for dissolution in cold alkali. Nord Pulp Pap Res J (accepted)

Coutiño AM, Lopes M (2019) LCA of an innovative cellulose textile fibre. In: Proceedings of 5th international conference of greening of industry network, Mexico City, pp. $427-443$

Frederick WJ, Krishnan R, Ayers RJ (1990) Pirssonite deposits in green liquor processing. Tappi J 73(2):135-140

Grönqvist S, Kamppuri T, Maloney T, Vehviläinen M, Liitia T, Suurnakki A (2015) Enhanced pre-treatment of cellulose pulp prior to dissolution into $\mathrm{NaOH} / \mathrm{ZnO}$. Cellulose 22(6):3981-3990. https://doi.org/10.1007/s10570-0150742-8

Kihlman M, Medronho B, Trey S, Stigsson L, Germgard U (2010) Cellunova: a future textile fibre concept based on a sustainable raw material. In: Proceedings 11th EWLP, Hamburg, pp 307-308

Kihlman M, Wawro D, Perzon E, Hedlund A, Germgard U (2012) Preparation of cellulosic fibres in semi-pilot scale from $\mathrm{NaOH}$-solutions. In: 243rd ACS national meeting \& exposition, San Diego

Kotilainen O (2017) Cooling crystallization of carbonate solutions. MSc Dissertation, Lappeenranta University of Technology

Michud A, Tanttu M, Asaadi S, Ma Y, Netti E, Kaariainen P, Persson A, Berntsson A, Hummel M, Sixta H (2016) Ioncell-F: ionic liquid-based cellulosic textile fibres as an alternative to viscose and Lyocell. Text Res J 86(5):543-552. 0040517515591774

Mozdyniewicz DJ, Nieminen K, Sixta H (2013) Alkaline steeping of dissolving pulp. Part I: cellulose degradation 
kinetics. Cellulose 20:1437-1451. https://doi.org/10.1007/ s10570-013-9926-2

NeoCel (2019) NeoCel Newsletter No 3. http://neocel.eu/ newsletters/. Accessed 22 Nov 2019

Öhman F, Theliander H (2007) Filtration properties of lignin precipitated from black liquor. Tappi J 6(7):3-9

Röder T, Moosbauer J, Wöss K, Schlader S, Kraft G (2013) Man-made cellulose fibres - a comparison based on morphology and mechanical properties. Lenzinger Berichte 91:7-12

Theliander H (1992) On the equilibrium of the causticizing reaction. Nord Pulp Pap Res J 7(2):81-87

Ulmgren P, Rådeström R, Edblad M, Wennerström M (1999) On the process chemistry of non-process elements in systems with a pressurized black liquor gasifier. J Pulp Pap Sci 25(10):344-350
Vehviläinen M, Kamppuri T, Rom M, Janicki J, Ciechanska D, Grönqvist S, Siika-Aho M, Christoffersson KE, Nousiainen P (2008) Effect of wet spinning parameters on the properties of novel cellulosic fibres. Cellulose 15(5):671-680. https://doi.org/10.1007/s10570-008-92193

Zakir T, Tran H, Papangelakis VG (2013) Formation of pirssonite in green liquor handling systems. Tappi J 20(7):33-41

Publisher's Note Springer Nature remains neutral with regard to jurisdictional claims in published maps and institutional affiliations. 